\title{
Model for Predictive Analysis of the Quantity of Water Evaporated during the Primary-Stage Processing of Bioceramic Material Sourced from Kaolin
}

\section{I. Nwoye ${ }^{1 *}$, K. Okeke ${ }^{2}$, M. C. Obi ${ }^{3}$, U. Nwanyanwu ${ }^{1}$, G. C. Obasi ${ }^{4}$ and O. O. Onyemaobi ${ }^{1}$}
${ }^{1}$ Dept.of Materials and Metallurgical Engineering, Federal University of Technology, Owerri, Nigeria.
${ }^{2}$ Dept. of Dental Technology, Federal University of Technology, Owerri, Imo State Nigeria. ${ }^{3}$ Dept. of Industrial Mathematics, Federal University of Technology, Owerri, Imo State Nigeria.
${ }^{4}$ Department of Material Science, Aveiro University, Portugal.

*Corresponding Author: chikeyn@yahoo.com

\begin{abstract}
Model for predicting the quantity of water evaporated during the primary-stage processing of a bioceramic material sourced from kaolin has been derived. The model; $E=$ $\operatorname{Exp}\left[0.3424(\log T)^{2.439}\right]$ shows that the quantity of evaporated water during the drying process is dependent on the drying temperature, the evaporating surface being constant. It was found that the validity of the model is rooted on the expression $(\log \beta \times \ln E)^{N}=\log T$ where both sides of the expression are correspondingly approximately equal to 2. The respective deviation of the model-predicted quantity of evaporated water from the corresponding experimental value was found to be less than 19\% which is quite within the acceptable deviation range of experimental results, hence depicting the usefulness of the model.
\end{abstract}

Keywords: Model, Water Evaporation, Processing, Bioceramic Material.

\section{INTRODUCTION}

Ceramics have been found [1] to comprise various kinds of non-metallic and inorganic materials. These include naturally occurring clays (kaolin) which is mainly alumino-silicates $\left(\mathrm{Al}_{2} \mathrm{O}_{3} \cdot 2 \mathrm{SiO}_{2} \cdot 2 \mathrm{H}_{2} \mathrm{O}\right)$ and carbides, nitrides, and oxides. Ceramic material can exist in the crystalline, amorphous, or glassy states.

Bioceramics and associated biomedical devices are used in many parts of the human body. Because human life and well being often depend on these devices there are stringent controls and constraints placed upon the application of devices and materials that can be used. It has been found [2] that when a prosthetic device is placed into the body, two aspects must be taken into account: biofunctionality and biocompatibility. 


\subsection{Biofunctionality}

This concerns the effect of the physiological environment on the material (bioceramics)/device. The material must satisfy its design requirements in service. The varied functions of bioceramics include: load transmission and stress distribution, e.g. bone replacement; articulation to allow movement, e.g. artificial knee joint; and space filling, e.g. cosmetic.

\subsection{Biocompatibility}

This is associated with the effect of the prosthetic device/material (and any degradation product) in the body. The material is not expected to degrade in its properties within the environment of the body and must not cause any adverse reactions within the host body.

\subsection{Nature of the Physiological Environment}

Studies [2] carried out on the effect of the physiological environment on biomaterials/device show that $\mathrm{NaCl}$ aqueous solution $(0.9 \mathrm{M})$ containing organic acids, proteins, enzymes, biological macromolecules, electrolytes and dissolved oxygen, nitrogen compounds, and soluble carbonates are environments where biomaterials and devices can operate favourable. It was found [2] that $\mathrm{pH} \approx 7.4$ is normal for physiological extracellular fluid. It has been discovered that cells (e.g inflammatory cells and fibrotic cells) secrete several complex compounds that may significantly affect an implanted biomaterial. Applications of these biomaterials/devices have been found [2] to be also dependent on mechanical environment: static, dynamic, stress, strain and friction.

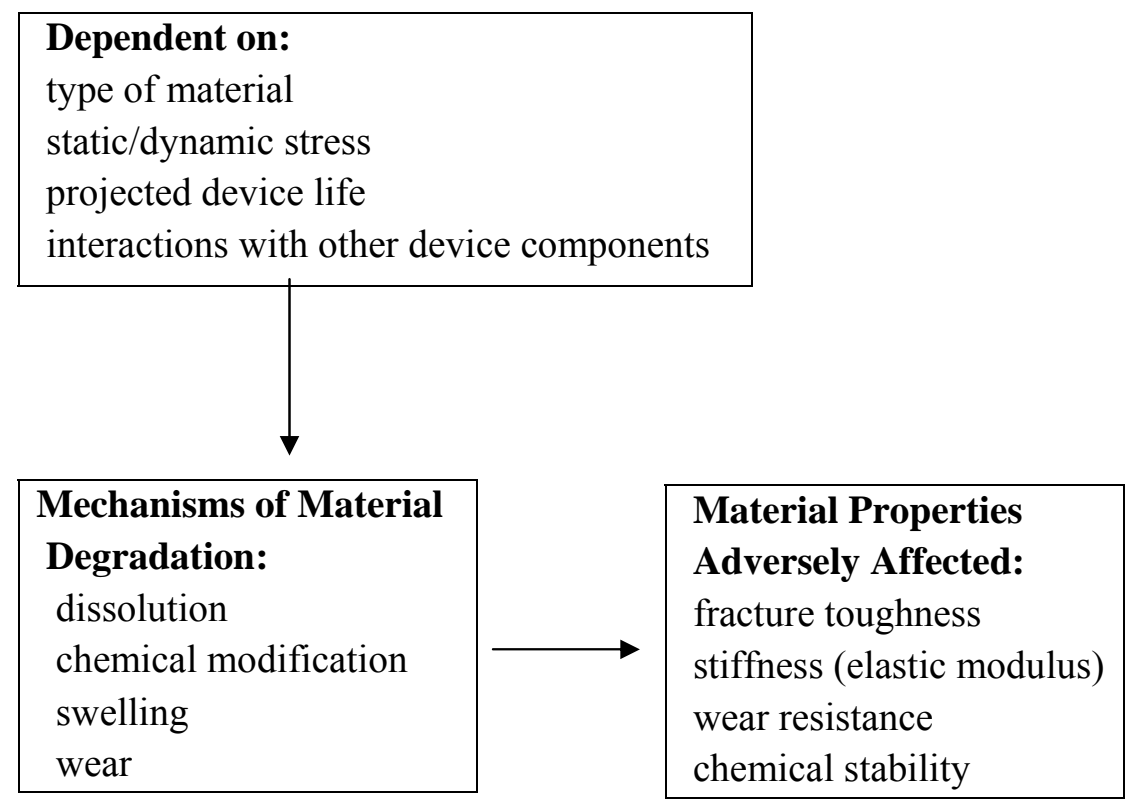

Fig. 1. The effect of the physiological environment on materials/devices [3]. 


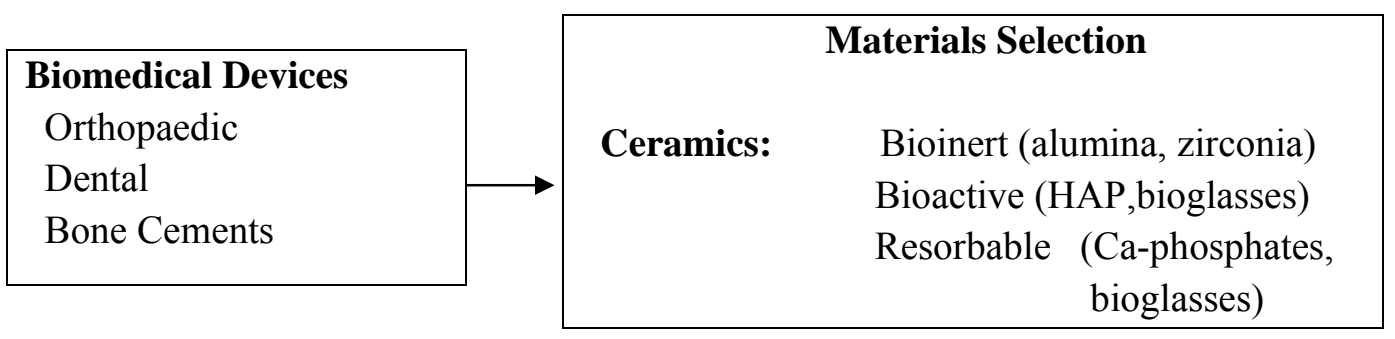

Fig. 2. Material selection for functional performance [3].

\subsection{Bioceramic Materials (Functional Properties)}

Ceramics are stiff, hard and chemically stable and are often used in situations where wear resistance is vital. Of the large number of ceramics known, only a few are suitably biocompatible. These ceramics can be grouped according to their relative reactivity in physiological environment. The main problem with ceramic component is that they are brittle and relatively difficult to process.

Studies [4] reveal three types of bioceramics; bioinert, bioactive and resorbable ceramics. Bioinert ceramics includes; alumina $\left(\mathrm{Al}_{2} \mathrm{O}_{3}\right)$, partially stabilized zirconia $\left(\mathrm{ZrO}_{2}\right)$ and silicone nitride $\left(\mathrm{Si}_{3} \mathrm{~N}_{4}\right)$. For these materials, foreign body response equals encapsulation. They were found [4] to be extremely stable and elicit minimal response to host tissues. The functional properties of bioinert ceramics were found [3] to include high compressive strength, excellent wear resistance and excellent bioinertness. Alumina has been found [3] to be a traditional bioinert material being chemically inert and highly stable oxide. It has been discovered that alumina has low fracture toughness and tensile strength implying that it can be used in compression only. Applications of alumina were found [3] to include femoral head of total hip replacement (polycrystalline) and single crystal (sapphire) in dental implants. It has been found that zirconia combines with a metal oxide dopant (stabilizing oxide- $\mathrm{MgO}$ or $\mathrm{Y}_{2} \mathrm{O}_{3}$ ) to form a ceramic known as partially stabilized zirconia (PSZ). This ceramic exhibits excellent toughness compared to other ceramics. This was found to be as result of a process known as transformation toughening [5]. This involved an energy absorbing phase change at the front of propagating crack tip which slows down the advancement of cracks. PSZ has been found to be useful in hip joint prosthesis.

It has been found [5] that bioactive ceramics direct chemical bond with tissue and in particular, bone. They are surface-reactive but have low solubility, allows fixation of implants in the skeletal system. Investigations [4] carried out on the properties of bioactive ceramics reveal that they are hydroxyapatite $\left(\mathrm{Ca}_{10}\left(\mathrm{PO}_{4}\right)_{6}(\mathrm{OH})_{2}\right)$ and bioglasses, having low mechanical strength and fracture toughness. It was reported [3] that bioactive ceramics can find application in: coatings 
used on stainless steel, $\mathrm{Ti}$ and $\mathrm{CoCr}$ for tissue on-growth, bone filler for dental and maxillofacial reconstruction.

It has been found [4] that resorbable ceramics are chemically broken down by the body and resorbed. This type of ceramic was also found [3] to control dissolution rate by composition and surface area (density). Investigations [3] indicate that chemicals produced as the ceramic is resorbed, are processed through the normal metabolic pathways of the body without evoking any deleterious effects. Chemically resorbable ceramics is made up of calcium phosphate e.g., tricalcium phosphate, $\mathrm{Ca}_{3}\left(\mathrm{PO}_{4}\right)_{2}$. This ceramic has found applications in bone repairs such as maxillofacial and periodontal defects, as well as in temporary scaffold or space-filler material [3].

Drying of clays through heating has been reported [6] to be associated with evaporation of water followed by formation of a hard but porous piece. Results of the study [6] reveal that a swollen appearance might occur during the release of some gases, but overall shrinkage must occur when vitrification sets in, leading to a strong dense piece.

Nwoye [7] derived a model for calculating the quantity of water lost by evaporation during oven drying of clay at $90^{\circ} \mathrm{C}$. The model;

$$
\gamma=\exp \left[(\operatorname{lnt})^{1.0638}-2.9206\right]
$$

indicated that the quantity of evaporated water, $\gamma$ during the drying process is dependent on the drying time $t$, the evaporating surface being constant. The validity of the model was found to be rooted in the expression $(\log \beta+\ln \gamma)^{\mathrm{N}}=\ln$.

Model for predictive analysis of the quantity of water evaporated during the primary-stage processing of a bioceramic material sourced from kaolin was derived by Nwoye et al. [8].

The model;

$$
\alpha=\mathrm{e}^{(\ln t 2.1992)}
$$

shows that the quantity of water $\alpha$, evaporated at $110^{\circ} \mathrm{C}$, during the drying process is also dependent on the drying time $t$, where the evaporating surface is constant. It was found that the validity of the model is rooted on the expression $(\ln t / \ln \alpha)^{N}=\log \beta$ where both sides of the expression are correspondingly approximately equal to 3 . The respective deviation of the modelpredicted quantity of evaporated water from the corresponding experimental value was found to be less than $22 \%$ which is quite within the acceptable deviation range of experimental results.

Model for quantifying the extent and magnitude of water evaporated during time dependent drying of clay has been derived [9]. The model;

$$
\gamma=\exp \left((\ln t / 2.9206)^{1.4}\right)
$$

indicates that the quantity of evaporated water $\gamma$ during the drying process (at $90^{\circ} \mathrm{C}$ ) is dependent on the drying time, $t$ the evaporating surface being constant. It was found that the validity of the model is rooted in the expression $\ln \gamma=(\ln t / \log \beta)^{\mathrm{N}}$ where both sides of the expression are correspondingly almost equal. 
Nwoye [10] derived a model for predicting the quantity of water evaporated during drying of clay at a temperature range $80-110^{\circ} \mathrm{C}$. The model;

$$
\mathrm{E}=\exp \left[0.3424(\log \mathrm{T})^{2.3529}\right]
$$

indicates that the quantity of evaporated water during the drying process is dependent on the drying temperature, the evaporating surface being constant. The validity of the model is rooted in the expression $(\ln E x \log \beta)^{N}=\log T$ since both sides of the expression are correspondingly approximately equal to 2 . The respective deviation of the model-predicted quantity of evaporated water from the corresponding experimental value is less than $20 \%$ which is quite within the acceptable deviation range of experimental results, hence depicting the usefulness of the model. Water evaporation per unit rise in the drying temperature evaluated from experimental and model-predicted results are 0.078 and $0.0502 \mathrm{~g} /{ }^{\circ} \mathrm{C}$ respectively, indicating proximate agreement.

It has been discovered that on drying clays through heating, water is given off. With time, a hard but porous piece forms. A swollen appearance might occur during the release of some gases, but overall shrinkage must occur when verifications set in leading to a strong dense piece [6].

The present work is to derive a model for predictive analysis of the quantity of water evaporated during the primary-stage processing of a bioceramic material sourced from kaolin (mined at Nsu (Nigeria)). Evaporation of water from the kaolinitic clay $\left(\mathrm{Al}_{2} \mathrm{O}_{3} \cdot 2 \mathrm{SiO}_{2} \cdot 2 \mathrm{H}_{2} \mathrm{O}\right)$ occurred in the course of drying the clay (in the oven) during the extraction of alumina $\left(\mathrm{Al}_{2} \mathrm{O}_{3}\right)$. The need for this extraction resulted from the indispensable role played by alumina (in biomedical engineering) as bioinert ceramics for total hip replacement.

\section{MODEL FORMULATION}

Experimental data obtained from research work [7] carried out at SynchroWell Research Laboratory, Enugu were used for this work. Results of the experiment used for the model formulation are as shown in Table 1.

Computational analysis of the experimental data [7] shown in Table 1, gave rise to Table 2 which indicate that;

$$
(\log \beta \times \ln E)^{N}=\log \mathrm{T} \quad \text { (approximately) }
$$

Introducing the value of $\mathrm{N}$ into equation (5)

$$
(\log \beta \times \ln \mathrm{E})^{0.41}=\log \mathrm{T}
$$

Since the inverse of $2.439=0.41$; equation (6) becomes;

$$
(\log \beta \times \ln \mathrm{E})^{1 / 2.439}=\log \mathrm{T}
$$

Multiplying the indices of both sides of equation (7) by 2.439

$$
\begin{aligned}
\log \beta \times \ln E & =(\log T)^{2.439} \\
\ln E & =\frac{(\log T)^{2.439}}{\log \beta}
\end{aligned}
$$


Introducing the value of $\beta$ into equation (9)

$$
\begin{aligned}
\ln \mathrm{E} & =\frac{(\log \mathrm{T})^{2.439}}{2.9206} \\
\ln \mathrm{E} & =0.3424(\log \mathrm{T})^{2.439} \\
\mathrm{E} & =\operatorname{Exp}\left[0.3424(\log \mathrm{T})^{2.439}\right]
\end{aligned}
$$

Where

$\mathrm{E}=$ Weight of evaporated water during the drying process $(\mathrm{g})$

$(\beta)=$ Area of evaporating surface $\left(\mathrm{mm}^{2}\right)$

$\mathrm{N}=0.41$; (Collapsibility coefficient of binder-clay particle boundary at the drying temperature range $80-110^{\circ} \mathrm{C}$ ) determined in the experiment [7].

$\mathrm{T}=$ Drying temperature $\left({ }^{0} \mathrm{C}\right)$.

Table 1. Variation of quantity of evaporated water with drying temperature [7].

\begin{tabular}{|l|c|c|}
\hline $\mathrm{T}\left({ }^{0} \mathrm{C}\right)$ & $(\beta)$ & $(\mathrm{E})$ \\
\hline 80 & 833 & 4.80 \\
85 & 833 & 5.71 \\
88 & 833 & 6.23 \\
90 & 833 & 6.60 \\
95 & 833 & 6.92 \\
110 & 833 & 8.60 \\
\hline
\end{tabular}

Table 2. Variation of $(\log \beta \times \ln E)^{\mathrm{N}}$ with $\log \mathrm{T}$.

\begin{tabular}{|c|c|c|c|}
\hline $\log T$ & $\log \beta$ & $\operatorname{InE}$ & $(\log \beta \times \ln E)^{\mathrm{N}}$ \\
\hline 1.9031 & 2.9206 & 1.5686 & 1.8664 \\
1.9294 & 2.9206 & 1.7422 & 1.9485 \\
1.9445 & 2.9206 & 1.8294 & 1.9879 \\
1.9542 & 2.9206 & 1.8871 & 2.0134 \\
1.9777 & 2.9206 & 1.9344 & 2.0339 \\
2.0414 & 2.9206 & 2.1518 & 2.1247 \\
\hline
\end{tabular}

\section{BOUNDARY AND INITIAL CONDITIONS}

Consider a rectangular shaped clay product of length $49 \mathrm{~mm}$, width $17 \mathrm{~mm}$, and breadth $9 \mathrm{~mm}$ exposed to drying in the furnace while it was in wet condition. Initially, atmospheric levels of oxygen are assumed. Atmospheric pressure was assumed to be acting on the clay samples during the drying process (since the furnace is not air-tight). The grain size of clay particles used is $425 \mu \mathrm{m}$, weight of clay and binder (bentonite) used (for each rectangular product): $100 \mathrm{~g}$ and $10 \mathrm{~g}$ respectively: quantity of water used for mixing: $2 \%$ (of total weight): drying temperature range 
used: $80-110^{\circ} \mathrm{C}$, area of evaporating surface: $833 \mathrm{~mm}^{2}$; and drying time used: $90 \mathrm{mins}$. These and other process conditions are detailed in the experimental technique [7].

The boundary conditions are: Atmospheric levels of oxygen at the top and bottom of the clay samples since they are dried under the atmospheric condition. No external force due to compression or tension was applied to the drying clays. The sides of the particles and the rectangular shaped clay products are taken to be symmetries.

\section{MODEL VALIDATION}

The formulated model was validated by direct analysis and comparison of the model-predicted E values and those from the experiment for equality or near equality.

Analysis and comparison between these E values reveal deviations of model-predicted E from those of the experimental values. This is believed to be due to the fact that the surface properties of the clay and the physiochemical interactions between the clay and binder, which were found to have played vital role during the evaporation process [7] were not considered during the model formulation. This necessitated the introduction of correction factor, to bring the modelpredicted $\mathrm{E}$ value to that of the corresponding experimental value (Table 3).

Deviation (Dv) (\%) of model-predicted $\mathrm{E}$ values from the experimental $\mathrm{E}$ values is given by $\mathrm{Dv}=\left(\frac{\mathrm{DP}-\mathrm{DE}}{\mathrm{DE}}\right) \times 100$

Where $\quad \mathrm{DP}=\mathrm{E}$ values predicted by model

$\mathrm{DE}=\mathrm{E}$ values obtained from experiment

Correction factor $(\mathrm{Cf})$ is the negative of the deviation i.e

$$
\mathrm{Cf}=-\mathrm{Dv}
$$

Therefore

$$
C f=-100\left(\frac{D P-D E}{D E}\right)
$$

Introduction of the value of $\mathrm{Cf}$ from equation (15) into the model gives exactly the corresponding experimental value of $\mathrm{E}$ [7].

\section{RESULTS AND DISCUSSION}

The derived model is equation (12). A comparison of the values of $E$ obtained from the experiment and those from the model shows low deviations hence depicting the reliability and validity of the model (Table 3). The respective deviation of the model-predicted quantity of evaporated water from the corresponding experimental value is less than $19 \%$ which is quite within the acceptable deviation range of experimental results, hence depicting the usefulness of the model. It was found that the validity of the model is rooted in the expression $(\log \beta \times \ln E)^{\mathrm{N}}=$ $\log \mathrm{T}$ where both sides of the expression are correspondingly approximately equal to 2 . Table 2 also agrees with equation (5) following the values of $(\log \beta \times \ln E)^{\mathrm{N}}$ and $\log \mathrm{T}$ evaluated from Table 1 as a result of corresponding computational analysis. 
Table 3. Comparison between quantities of evaporated water as predicted by model and as obtained from experiment [7].

\begin{tabular}{|l|c|c|c|}
\hline $\mathrm{E}_{\exp }$ & $\mathrm{E}_{\mathrm{M}}$ & $\mathrm{Dv}(\%)$ & $\mathrm{Cf}(\%)$ \\
\hline 4.80 & 5.1805 & +7.93 & -7.93 \\
5.71 & 5.4789 & -4.05 & +4.05 \\
6.23 & 5.6607 & -9.14 & +9.14 \\
6.60 & 5.7818 & -12.40 & +12.40 \\
6.92 & 6.0899 & -12.00 & +12.00 \\
8.60 & 7.0418 & -18.12 & +18.12 \\
\hline
\end{tabular}

Where $\quad E_{\text {exp }}=$ E values obtained from experiment [7]

$\mathrm{E}_{\mathrm{M}}=\mathrm{E}$ values predicted by model.

\section{CONCLUSION}

The model predicts the quantity of water evaporated during the primary-stage processing of a bioceramic material sourced from kaolin. It was found that the validity of the model is rooted in the expression $(\log \beta \times \ln E)^{N}=\log \mathrm{T}$ where both sides of the expression are correspondingly approximately equal to 2 . The respective deviation of the model-predicted quantity of evaporated water from the corresponding experimental value is less than $19 \%$ which is quite within the acceptable deviation range of experimental results, hence depicting the usefulness of the model.

Further works should incorporate more process parameters into the model with the aim of reducing the deviations of the model-predicted $\mathrm{E}$ values from those of the experimental.

\section{ACKNOWLEDGEMENT}

The authors thank Dr. Ekeme Udoh, a modelling expert at Linkwell Modelling Centre Calabar for his technical inputs. The management of SynchroWell Nig. Ltd. Enugu is also appreciated for permitting and providing the experimental data used in this work.

\section{REFERENCES.}

[1] Ijomah, M. N .C., (1992). The Structure and Properties of Engineering Materials, Christon Publishers, Awka, Nigeria, pp.69.

[2] Hill, D., (1998). Design Engineering of Biomaterials for Medical Devices, John Wiley \& Sons, Chichester, pp.70.

[3] Biomedical Materials (2001). Material Science and Engineering- UNSW, Teachers Reference. 
[4] Schlenker, B. R., (1974). Introduction to Material Science, SI Edition, John Wiley \& Sons, Milton, pp. 65.

[5] Almath Crucible Ltd.Website: http://www.almath.vispa.co.uk/zirconia.htm

[6] Singer, F. and Singer, S.S., (1963). Industrial Ceramics, University Press Cambridge, pp. 44.

[7] Nwoye, C. I., (2009). Model for Calculating the Quantity of Water Lost by Evaporation during Oven Drying of Clay. Researcher Journal, 1(3): 8-13.

[8] Nwoye, C. I., Okeke, K., Obi, M., Nwanyanwu, U., Ofoegbu, S. (2009). Model for Predictive Analysis of the Quantity of Water Evaporated during the Primary-Stage Processing of Bioceramic Material Sourced from Kaolin. J. Nat. Sc., 7(4): 79-84.

[9] Nwoye, C. I., Nwakwuo, C. C., Obi, M. C., Obasi, G. C., Onyemaobi, O. O., (2009). Model for Quantifying the Extent and Magnitude of Water Evaporated during Time Dependent Drying of Clay. New York J. Sc. 2(3): 55-58.

[10] Nwoye, C. I., (2009). Model for Predicting the Quantity of Water Evaporated during Initial Stage Drying of Wet Clay Designated for Production of Bricks. J. Min., Mat., Characterization \& Eng. 8(8):647-658.

[11] Nwoye, C. I., (2006). SynchroWell Research Work Report, DFM Unit, No 2487156, 12-20. 